\title{
Influence of the Short-term Intake of High Doses of Solifenacin and Trospium on Cognitive Function and Health-Related Quality of Life in Older Women With Urinary Incontinence
}

\author{
Kirill Kosilov' ${ }^{1}$, Irina Kuzina ${ }^{1}$, Sergay Loparev ${ }^{2}$, Yuliya Gainullina ${ }^{1}$, Liliya Kosilova ${ }^{3}$, Alexandra Prokofyeva ${ }^{1}$ \\ ${ }^{1}$ Department of Social Sciences, School of Humanities, Far Eastern Federal University, Vladivostok, Russian Federation \\ ${ }^{2}$ Department of Urology, City polyclinic No. 3, Vladivostok, Russian Federation \\ ${ }^{3}$ Department of Functional Diagnostics, Med. Association No. 2 of Vladivostok, Vladivostok, Russian Federation
}

Purpose: The aim of this study was to investigate the safety and the effects of elevated doses of solifenacin and trospium on cognitive function and health-related quality of life (HRQoL) in elderly women receiving treatment for urinary incontinence. Methods: The study included 312 women aged 60-83 years (mean age, 69.4 years). All participants had scored at least 24 points on the Mini-Mental State Examination (MMSE) scale, and all of them had been diagnosed with urge urinary incontinence (UUI) or mixed urinary incontinence (MUI). The women were randomly assigned to 3 groups: group A, individuals who were simultaneously administered solifenacin at a high dosage of $20 \mathrm{mg}$ per day and trospium at a high dosage of $60 \mathrm{mg}$ per day; group B, persons taking solifenacin and trospium at the usual dosage of 10 and $30 \mathrm{mg}$ per day, respectively; and group C, persons who received a placebo. Participants' cognitive status was assessed by the MMSE, Controlled Oral Word Association Test, Wechsler Adult Intelligence Scale-Revised, Wechsler Memory Scale III, Colour Trails Test, and California Verbal Learning Test scales. The HRQoL assessment was performed using the Medical Outcomes Study 36-Item Health Survey.

Results: The cognitive function parameters did not differ at the start and end of the study across the groups $(\mathrm{P}>0.05)$. Additionally, the cognitive function parameters did not differ significantly within each group between the start and end of the study $(\mathrm{P}>0.05)$. The values of most HRQoL parameters regarding the functional state of the lower urinary tract (LUT) after the termination of treatment significantly improved in groups A and $\mathrm{B}(\mathrm{P}<0.05)$. A significant correlation between cognitive status and HRQoL or LUT parameters was absent $(\mathrm{r}<0.3)$, while the correlations between HRQoL and LUT parameters were $\mathrm{r}=0.31-0.83, \mathrm{P}<0.05$.

Conclusions: The use of elevated doses of solifenacin and trospium did not increase the risk of cognitive impairment in women with UUI and MUI. The combination of solifenacin and trospium at a double dosage may be recommended to elderly women with treatment-resistant symptoms of UUI and MUI. However, the safety of combining antimuscarinic drugs in women with an increased volume of residual urine requires further study.

Keywords: Muscarinic antagonists; Cognition disorders; Quality of life; Urinary incontinence

- Research Ethics: All procedures performed in studies involving human participants were in accordance with the ethical standards of the institutional and/or national research committee and with the 1964 Helsinki declaration and its later amendments or comparable ethical standards. Informed consent was obtained from all individual participants included in the study. The design of the study was approved by the ethical committee of the Far Eastern State University (00218-M-1012015)

- Conflict of Interest: No potential conflict of interest relevant to this article was reported.

Corresponding author: Kirill Kosilov (iD https://orcid.org/0000-0001-9747-3100 Department of Social Sciences, School of Humanities, Far Eastern Federal University, Vladivostok, Ayax 10, F733, DVFU, Vladivostok, Russian Federation E-mail: oton2000@mail.ru / Tel: +7-914-717-3915 / Fax: +7-4232-457-693 Submitted: October 4, 2017 / Accepted after revision: January 27, 2018
This is an Open Access article distributed under the terms of the Creative Commons Attribution Non-Commercial License (http://creativecommons.org/licenses/by-nc/4.0/) which permits unrestricted non-commercial use, distribution, and reproduction in any medium, provided the original work is properly cited. 


\section{INTRODUCTION}

According to the recommendations of the International Continence Society and the International Statistical Classification of Diseases and Related Health Problems, the term "urinary incontinence" includes urge urinary incontinence (UUI), stress urinary incontinence, and mixed urinary incontinence (MUI) [1]. The causes of UUI and MUI in middle-aged and elderly women are breakdown of the function of intramural ganglia and afferent detrusor structures, breakdown of the function of the urothelial muscarinic receptors, and weakening of the pelvic floor muscles and pelvic organs [2]. The prevalence of UUI and MUI is very high, ranging from $16 \%-19 \%$ in middle-aged women to $44 \%$ in older women [3,4]. Urinary incontinence adversely affects health-related quality of life (HRQoL), reduces labour productivity, and can lead to significant economic costs $[5,6]$.

The most effective drugs for treating UUI and MUI are antimuscarinic (AM) drugs. AM drugs are successfully used in the treatment of symptoms of bladder hyperactivity and urinary incontinence in elderly women [7-9]. Although the first-generation AM drugs caused numerous side effects and were often rejected by patients [10], the AM drugs that are currently in common use - solifenacin, trospium, and some others - are considered safe for prolonged use by the elderly [11]. However, in some cases, standard doses of AMs are insufficient to obtain a satisfactory effect [12]. Possible solutions for treatment-resis- tant UUI include increasing the dose of AM and the duration of treatment, as well as combining 2 AMs. Previously, it was shown that higher doses of solifenacin and trospium did not affect the level of side effects [13]. Evidence has been reported that oxybutynin and tolterodine can cause cognitive dysfunction in some patients $[14,15]$. At the same time, solifenacin and trospium in standard dosages do not affect patients' cognitive ability. This is due to the limited ability of these drugs to penetrate the blood-brain barrier $[16,17]$. In earlier studies, we determined that elevated dosages of solifenacin and trospium, when taken concomitantly, did not increase the number of side effects in older women $[18,19]$. However, the possible effect of the combination of these AMs on cognitive function has not been investigated, although many researchers continue to recommend caution regarding the use of AMs in elderly people $[20,21]$.

In addition, the possible effects of the simultaneous administration of higher doses of solifenacin and trospium on HRQoL have not been studied [22].

Thus, the aim of our study was to investigate cognitive function and HRQoL in individuals taking a combination of solifenacin and trospium at higher-than-usual dosages.

\section{MATERIALS AND METHODS}

\section{Participants and Algorithm}

A total of 312 women aged $60-83$ years (mean age, 69.4 years)

Table 1. Functional state of lower urinary tract of women with urge urinary incontinence before treatment $(\mathrm{n}=312)$

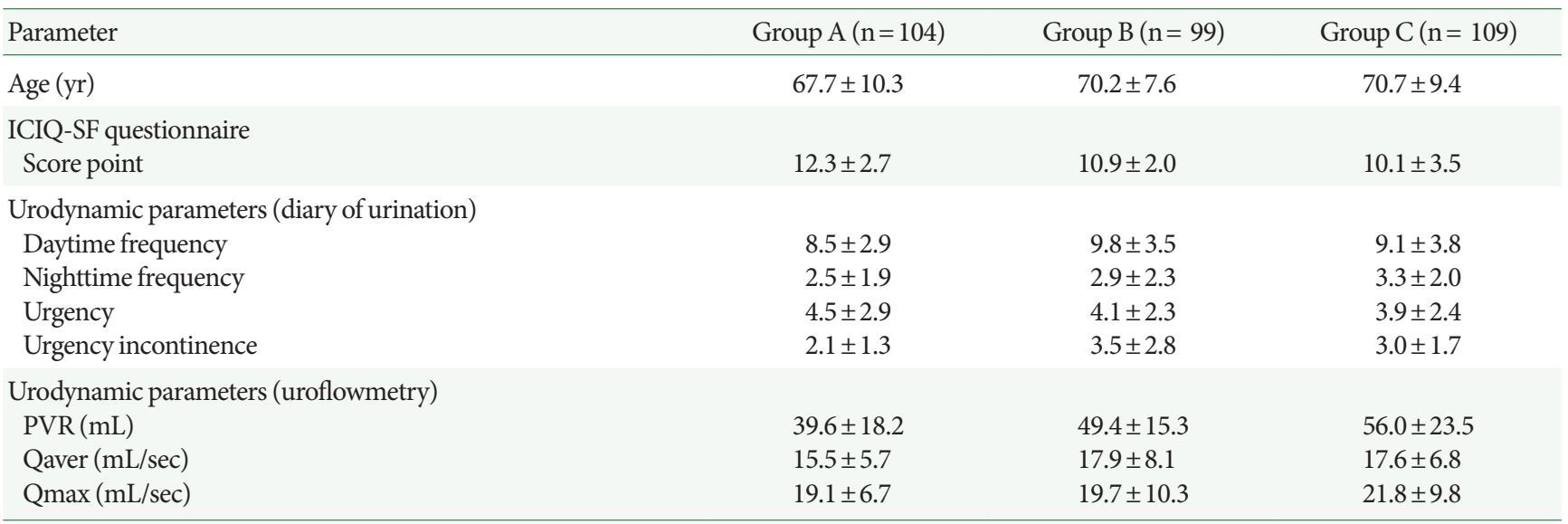

Values are presented as mean \pm standard deviation.

Group A, solifenacin $20 \mathrm{mg}$ + trospium $60 \mathrm{mg}$ per day; group B, solifenacin $10 \mathrm{mg}$ + trospium $30 \mathrm{mg}$ per day; group C, control (placebo); ICIQ-SF, International Consultation on Incontinence Questionnaire-Short Form; PVR, postvoid residual (urine volume); Qaver, average flow rate; Qmax, maximum flow rate.

P-value $>0.05$ in all cases (differences between groups are unreliable). 
participated in a cohort randomized trial. The groups included persons diagnosed with UUI (ICD-10-CM N39.41) or MUI (ICD-10-CM N39.46), who had previously received AM treatment, but did not experience the expected effect or experienced a short-lived therapeutic effect. The group included women who scored at least 24 on the Mini-Mental State Examination (MMSE) scale and gave written informed consent to participate in the experiment [21,23]. All participants scored 6 or more points on the International Consultation on Incontinence Questionnaire-Short Form (ICIQ-SF) and had at least 2 urge episodes per day, according to their voiding diary. All patients had previously taken 2 or more AM drugs within the last 3 months before the study.

The exclusion criteria were the presence of depression, organic brain diseases, cerebral circulatory disorders, epilepsy, Parkinson disease, Alzheimer disease, alcoholism, or any chronic somatic disease in the acute stage. The characteristics of the patients' lower urinary tract function are presented in Table 1.

The study was conducted at the urological department of the city polyclinic No. 3 in Vladivostok, Russia, and at the Far Eastern Federal University from February 15, 2015 to May 5, 2016. All patients were randomly assigned to 3 groups. Group A included persons who simultaneously received solifenacin at a high dosage of $20 \mathrm{mg}$ per day and trospium at a high dosage of $60 \mathrm{mg}$ per day. Group B included women who simultaneously received solifenacin and trospium at the standard recommended dosage of 10 and $30 \mathrm{mg}$ per day, respectively. Group C included women who received a placebo. Before the experiment, all patients received written instructions for taking the AMs, including a reminder of the need to strictly adhere to the daily dose. All women, in accordance with the instructions, recorded when they took the drug in a special column of their voiding diary. All participants were recommended not to discontinue the medication in the event of a side effect, and to report the problem to the researchers. If the side effect was intolerable, the AMs were discontinued. The researchers checked that the participants were taking the drugs once a week by phone throughout the 8 weeks of the experiment. Lower urinary tract function did not change throughout the study in any of the 3 groups (Table 1) [19].

Before the start of the study, and after its completion, lower urinary tract conditions, cognitive functions, and mental status, as well as HRQoL, were tested. The design of the study is presented in Fig. 1. The implementation of the ethical standards established by the Helsinki Declaration was compulsory. The design of the study was approved by the local ethics committee.

\section{Measures and Statistical Analysis Neurourological assessment}

To assess the functional state of the lower urinary tract, we used

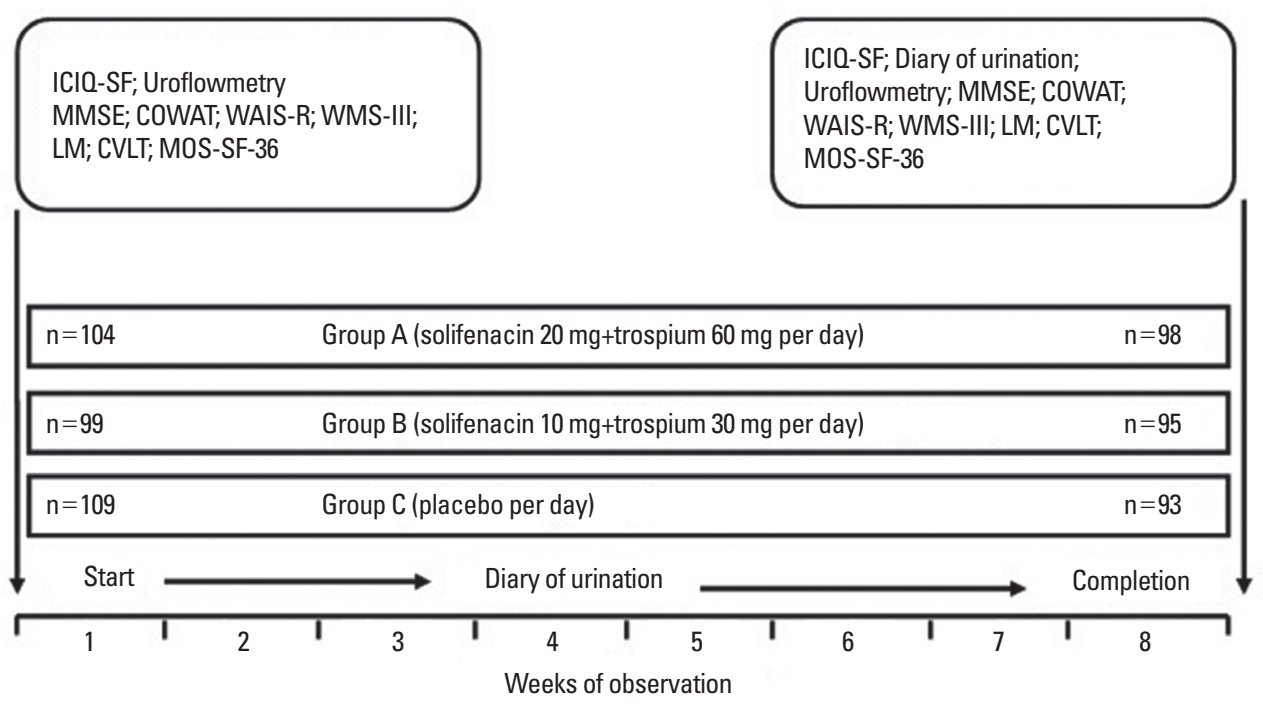

Fig. 1. Algorithm of examination and treatment of patients with urge urinary incontinence $(n=312)$. ICIQ-SF, International Consultation on Incontinence Questionnaire-Short Form (score point); MMSE, Mini-Mental State Examination; COWAT, Controlled Oral Word Association Test; WAIS-R, Wechsler Adult Intelligence Scale-Revised; WMS-III, Wechsler Memory Scale III; LM, logic memory; CVLT, California Verbal Learning Test; MOS-SF-36, Medical Outcomes Study 36-Item Short-Form. 
the ICIQ-SF questionnaire, which includes 2 main sections [24]. Subsections 3, 4, and 5 describe lower urinary tract symptoms (LUTS), including the number of episodes of incontinence on a scale of 0 to 21 points. Throughout the observation period, patients filled out a daily voiding diary [25], in which they noted the time and number of episodes of UUI and incontinence. At the start and at the end of the study, all patients underwent uroflowmetry to measure the postvoid residual urine volume.

\section{Neuropsychological assessment}

The MMSE was used to assess the following areas of cognitive function: orientation, registration, attention and calculation, and recall and language [23]. Verbal fluency was tested using the Controlled Oral Word Association Test. To estimate attention and reversing operations (mental double-tracking), the digit span test from the Wechsler Adult Intelligence Scale-Revised (WAIS-R) was used. The working memory and visualspatial processing in elderly women was studied using the Wechsler Memory Scale III test, and short- and long-term organized verbal memory was tested using the logical memory test. The California Verbal Learning Test was used to measure verbal learning abilities and memory. The effectiveness of visual search and psychomotor reactions was assessed by the Colour Trails Test (CTT).

\section{Assessment of HRQoL}

The Medical Outcomes Study 36-Item Health Survey was used to evaluate HRQoL in elderly women with urinary incontinence. This questionnaire contains 8 independent scales: vitality, physical functioning $(\mathrm{PF})$, bodily pain, general health perceptions (GHP), physical role functioning (PRF), emotional role functioning (ERF), social role functioning (SRF), and mental health. Each of these scales contains 4-6 levels. The total score is from 0.30 to 1.0 points. This tool is valid and sensitive to the quality of life parameters that can be impaired in individuals with UUI $[26,27]$. The survey at the beginning and at the end of the experiment was administered by 2 independent interviewers, who were not familiar with each other, and the patients were not aware of the purpose and algorithm of the experiment. After completion, each questionnaire was assigned a cipher for depersonalizing the data. The questionnaires were then sent for statistical processing by the research team.

\section{Statistical Analysis}

The data were processed using JMP SAS Statistical Discovery 8.0.2 (SAS Institute Inc., Cary, NC, USA). The results are presented as the mean \pm standard deviation for continuous variables. The significance of the differences between the mean values in the samples with a normal distribution was estimated by the Student t-test. Differences in the distribution of variables were compared using the Mann-Whitney U-test. The Spearman coefficient was used to determine the correlation between the samples. Correlations within the range of $r=0.6-1.0$ were considered strong, values of $r$ between 0.30 and 0.59 were considered to indicate a moderate correlation, and values of $r$ between 0.1 and 0.29 indicated a weak correlation. P-values of $<0.05$ were considered to indicate statistical significance.

\section{RESULTS}

Twenty-six women (8.3\%)discontinued participation in the study for various reasons. In group A, treatment was refused by 6 women (5.8\%), in group B by 4 women (4.0\%), and in group C by 18 women (16.5\%). Eleven participants in group C discontinued treatment after the first month, citing the lack of an effect; the others did not explain why they dropped out of the study. In group A, 5 people discontinued the study because of dry mouth and constipation, and 1 woman did not explain her reasons for discontinuation. In group B, 2 patients interrupted the treatment due to dry mouth, and 2 more because of the lack of an effect.

One of the criteria for selecting participants was normal cognitive function. Thus, the initial (baseline) values of cognitive function parameters in all patients corresponded to the norm and did not differ to a statistically significant extent. Before the start of treatment, HRQoL was investigated in all patients, and no statistically significant differences in HRQoL among the 3 groups were found.

The scores for PF, GHP, PRF, ERF, and SRF in groups A and $B$ were significantly higher after treatment than before treatment (Table 2). After treatment in these groups, the indicators of lower urinary tract function also changed. The ICIQ-SF scores, the number of episodes of urgency, and the frequency of urinary incontinence in groups A and B significantly decreased, while the residual urine volume increased.

We also analysed the reliability of the between-group differences after treatment. It was found that there were no significant differences in cognitive function among the 3 groups. 
Table 2. Descriptive statistics of the cognitive status, HRQoL, and functional status LUT in women with urge urinary incontinence after treatment $(\mathrm{n}=312)$

\begin{tabular}{|c|c|c|c|c|c|c|}
\hline \multirow{2}{*}{ Parameter } & \multirow{2}{*}{$\begin{array}{l}\text { Group A } \\
(n=104)\end{array}$} & \multirow{2}{*}{$\begin{array}{l}\text { Group B } \\
(\mathrm{n}=99)\end{array}$} & \multirow{2}{*}{$\begin{array}{l}\text { Group C } \\
(n=109)\end{array}$} & \multicolumn{3}{|c|}{ Q value } \\
\hline & & & & $\mathrm{A} / \mathrm{B}$ & $\mathrm{B} / \mathrm{C}$ & $\mathrm{A} / \mathrm{C}$ \\
\hline \multicolumn{7}{|l|}{ Cognitive status } \\
\hline Mini-Mental State Examination & $26.0 \pm 3.0$ & $27.1 \pm 1.3$ & $28.4 \pm 1.9$ & 0.18 & 0.26 & 0.20 \\
\hline Controlled Oral Word Association Test & $14.5 \pm 5.7$ & $15.8 \pm 3.5$ & $15.1 \pm 5.0$ & 0.17 & 0.09 & 0.20 \\
\hline Digit span forward (WAIS-RF) & $4.8 \pm 1.4$ & $4.9 \pm 1.2$ & $5.1 \pm 2.1$ & 0.13 & 0.05 & 0.14 \\
\hline Digit span backward (WAIS-RB) & $4.1 \pm 1.4$ & $3.8 \pm 2.4$ & $3.9 \pm 1.3$ & 0.14 & 0.04 & 0.06 \\
\hline The Color Trails Test 1 (CTT1) & $59.8 \pm 18.4$ & $56.2 \pm 25.0$ & $54.2 \pm 19.7$ & 0.15 & 0.12 & 0.04 \\
\hline The Color Trails Test 2 (CTT2) & $131.6 \pm 27.7$ & $123.6 \pm 29.5$ & $125.2 \pm 18.4$ & 0.04 & 0.07 & 0.12 \\
\hline Spatial span forward (WMS-III) & $5.9 \pm 1.2$ & $5.2 \pm 2.4$ & $6.3 \pm 2.2$ & 0.03 & 0.02 & 0.18 \\
\hline Spatial span backward (WMS-III) & $6.2 \pm 2.0$ & $7.5 \pm 2.4$ & $7.2 \pm 1.4$ & 0.11 & 0.04 & 0.15 \\
\hline Logic memory 1 recall (WMS-III) & $37.9 \pm 5.9$ & $39.2 \pm 10.1$ & $41.4 \pm 13.5$ & 0.05 & 0.03 & 0.10 \\
\hline Logic memory 2 recall (WMS-III) & $21.4 \pm 9.1$ & $18.9 \pm 10.4$ & $22.0 \pm 16.1$ & 0.09 & 0.04 & 0.03 \\
\hline Logic memory 2 recognition (WMS-III) & $23.4 \pm 5.1$ & $25.1 \pm 5.9$ & $27.5 \pm 4.2$ & 0.03 & 0.05 & 0.16 \\
\hline Logic memory $2 \%$ retention (WMS-III) & $89.7 \pm 14.1$ & $88.5 \pm 12.4$ & $91.2 \pm 17.5$ & 0.28 & 0.19 & 0.27 \\
\hline California Verbal Learning Test TL & $48.3 \pm 10.3$ & $55.2 \pm 12.5$ & $56.3 \pm 16.3$ & 0.10 & 0.05 & 0.04 \\
\hline California Verbal Learning Test SDFR & $10.4 \pm 7.7$ & $10.2 \pm 5.3$ & $8.9 \pm 6.1$ & 0.16 & 0.18 & 0.14 \\
\hline California Verbal Learning Test SDCR & $12.7 \pm 7.0$ & $13.0 \pm 5.3$ & $11.6 \pm 6.9$ & 0.13 & 0.04 & 0.17 \\
\hline California Verbal Learning Test LDFR & $12.1 \pm 5.1$ & $9.9 \pm 4.9$ & $10.6 \pm 5.5$ & 0.09 & 0.06 & 0.10 \\
\hline California Verbal Learning Test LDCR & $12.0 \pm 3.5$ & $11.0 \pm 3.3$ & $11.1 \pm 4.0$ & 0.07 & 0.12 & 0.08 \\
\hline \multicolumn{7}{|l|}{ Health-related quality of life } \\
\hline MOS-36 vitality & $71.3 \pm 23.7$ & $71.6 \pm 21.0$ & $73.4 \pm 19.2$ & 0.45 & 0.33 & 0.36 \\
\hline MOS-36 physical functioning & $83.3 \pm 10.1^{*}$ & $81.4 \pm 21.4^{*}$ & $49.0 \pm 8.1$ & 0.05 & 0.01 & 0.01 \\
\hline MOS-36 bodily pain & $19.7 \pm 14.4$ & $25.3 \pm 10.3$ & $26.7 \pm 18.0$ & 0.16 & 0.02 & 0.02 \\
\hline MOS-36 general health perceptions & $80.1 \pm 12.4^{*}$ & $82.8 \pm 10.9^{*}$ & $62.4 \pm 6.7$ & 0.09 & 0.01 & 0.01 \\
\hline MOS-36 physical role functioning & $78.1 \pm 11.7^{\star}$ & $71.4 \pm 10.2^{*}$ & $51.6 \pm 9.2$ & 0.03 & 0.01 & 0.01 \\
\hline MOS-36 emotional role functioning & $81.5 \pm 9.1^{\star *}$ & $84.3 \pm 13.3^{*}$ & $55.7 \pm 7.2$ & 0.12 & 0.01 & 0.01 \\
\hline MOS-36 social role functioning & $86.7 \pm 9.6$ & $65.3 \pm 9.2^{\star}$ & $45.7 \pm 8.1$ & 0.01 & 0.01 & 0.01 \\
\hline MOS-36 mental health & $75.1 \pm 10.5$ & $65.4 \pm 9.8$ & $61.4 \pm 13.3$ & 0.19 & 0.02 & 0.13 \\
\hline \multicolumn{7}{|l|}{ Lower urinary tract status } \\
\hline Uroflowmetry PVR (mL) & $19.0 \pm 15.3^{*}$ & $25.4 \pm 16.1^{*}$ & $54.1 \pm 9.7$ & 0.02 & 0.01 & 0.01 \\
\hline Uroflowmetry Qaver (mL/sec) & $19.3 \pm 6.3$ & $22.1 \pm 4.9$ & $18.1 \pm 5.0$ & 0.19 & 0.22 & 0.18 \\
\hline Diary/urgency & $0.8 \pm 0.5^{\star}$ & $1.4 \pm 0.9^{*}$ & $2.2 \pm 0.7$ & 0.03 & 0.01 & 0.01 \\
\hline Diary/urgency urinary incontinence & $0.5 \pm 0.2^{\star *}$ & $1.3 \pm 0.4^{*}$ & $2.1 \pm 0.6$ & 0.01 & 0.02 & 0.01 \\
\hline ICIQ-SF, score point & $5.9 \pm 0.7^{\star *}$ & $7.5 \pm 1.2^{\star *}$ & $10.6 \pm 1.5$ & 0.02 & 0.01 & 0.01 \\
\hline
\end{tabular}

Values are presented as mean \pm standard deviation.

Parameter values for the patient's cognitive status scales and the functional state of the lower urinary tract (LUT) are given in scores, health-related quality of life (HRQoL) scales are in \%, for uroflowmetry in units indicated in the table.

Group A, solifenacin $20 \mathrm{mg}+$ trospium $60 \mathrm{mg}$ per day; group B, solifenacin $10 \mathrm{mg}+$ trospium $30 \mathrm{mg}$ per day; group C, control (placebo); WAIS-R, Wechsler Adult Intelligence Scale-Revised; WAIS-RF, digit span forward; WAIS-RB, digit span backward; WMS-III, Wechsler Memory Scale III; SDFR, short-delay free recall; SDCR, short-delay cued recall; LDFR, long-delay free recall; LDCR, long-delay cued recall; MOS-36, Medical Outcomes Study 36-Item (MOS-36) Health Survey; ICIQ-SF, International Consultation on Incontinence Questionnaire-Short Form; PVR, postvoid residual (urine volume); Diary/urgency, urgency incontinence-episodes of day; Qaver, average flow rate.

${ }^{\star} \mathrm{P}<0.05,{ }^{* \star} \mathrm{P}<0.01$, comparing between the same group before and after treatment $(\mathrm{A} / \mathrm{A} ; \mathrm{B} / \mathrm{B} ; \mathrm{C} / \mathrm{C})$. Q-multiple comparisons with Bonferroni amendment. Critical P-value level $<0.017$.

However, the HRQoL parameters and the functional state of the urinary tract were significantly different. The scores for PF, GHP, PRF, ERF, and SRF in groups A and B were significantly higher than in group C. In these groups, the ICIQ-SF scores, the number of episodes of urgency, and the frequency of uri- nary incontinence were significantly lower than in group C.

Changes in the parameters of the cognitive status of patients before and after treatment are shown in Fig. 2. According to our data, these changes were within the statistical margin of error.

No correlation was found between the values of HRQoL pa- 


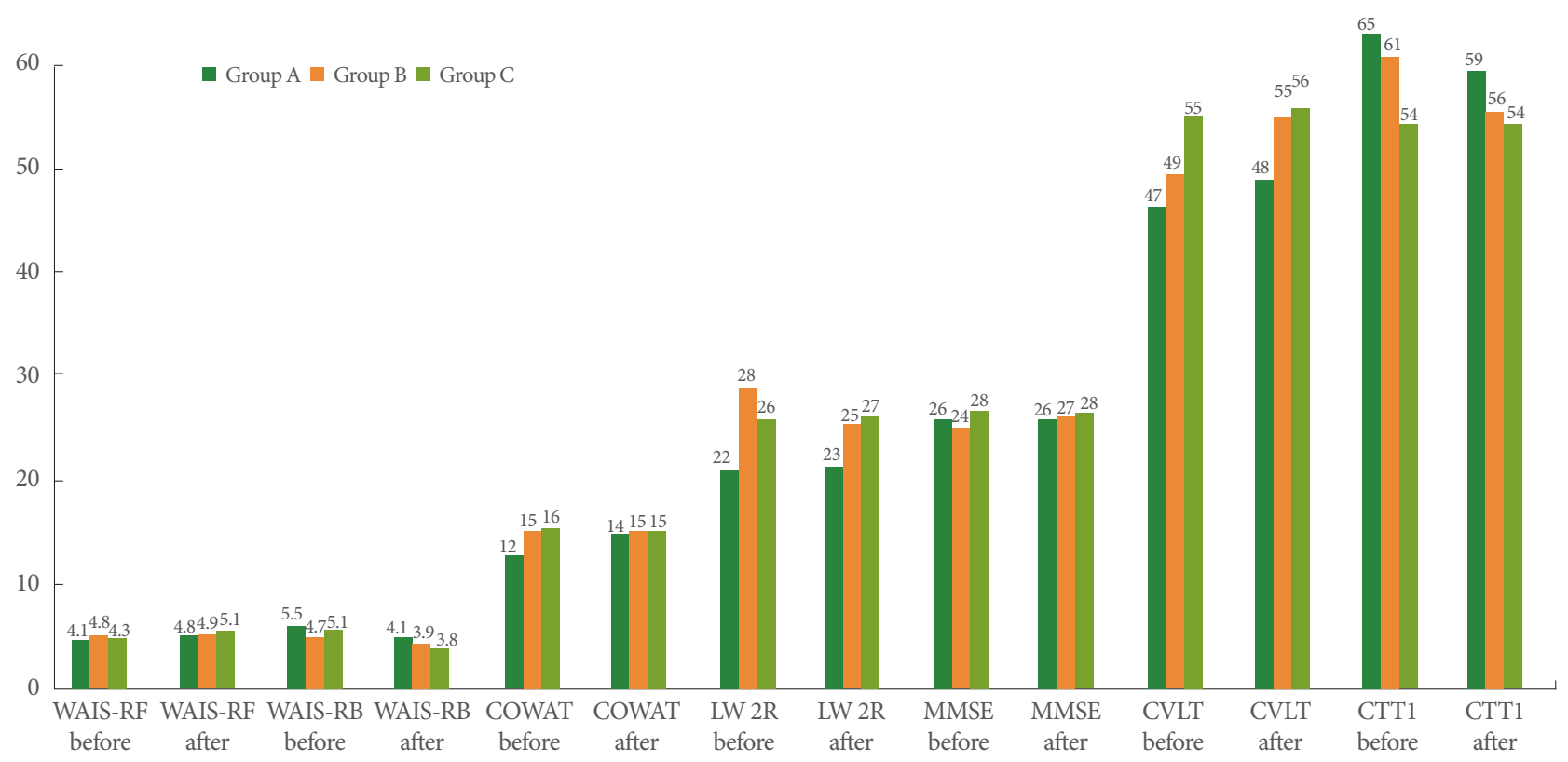

Fig. 2. The relationship between assessment of level of cognitive performance before and after of treatment ( $n=312)$. WAIS-R, Wechsler Adult Intelligence Scale-Revised; WAIS-RF, digit span forward; WAIS-RB, digit span backward; COWAT, Controlled Oral Word Association Test; LM 2R, logic memory 2 recognition (WMS-III); MMSE, Mini-Mental State Examination; CVLT TL, California Verbal Learning Test TL; CTT1, Color Trails Test 1. Group A, solifenacin 20 mg+trospium 60 mg per day; group B, solifenacin 10 mg+trospium $30 \mathrm{mg}$ per day; group C, control (placebo).

Table 3. The relationship between assessment of the HRQoL, level of cognitive performance and the symptoms of lower urinary tract after treatment by solifenacin according Spearman coefficient $(\mathrm{n}=312)$

\begin{tabular}{|c|c|c|c|c|c|c|c|c|c|c|c|c|c|c|c|}
\hline \multirow{4}{*}{ Variable } & \multicolumn{15}{|c|}{ Health-related quality of life marker (MOS-36SF) } \\
\hline & \multicolumn{3}{|c|}{$\mathrm{PF}$} & \multicolumn{3}{|c|}{ GHP } & \multicolumn{3}{|c|}{ PRF } & \multicolumn{3}{|c|}{ ERF } & \multicolumn{3}{|c|}{ SRF } \\
\hline & \multicolumn{3}{|c|}{ Group } & \multicolumn{3}{|c|}{ Group } & \multicolumn{3}{|c|}{ Group } & \multicolumn{3}{|c|}{ Group } & \multicolumn{3}{|c|}{ Group } \\
\hline & A & $\mathrm{B}$ & $\mathrm{C}$ & A & B & $\mathrm{C}$ & A & B & $\mathrm{C}$ & A & $\mathrm{B}$ & $\mathrm{C}$ & A & B & $\mathrm{C}$ \\
\hline \multicolumn{16}{|l|}{ Cognitive marker } \\
\hline MMSE & 0.29 & 0.24 & 0.25 & 0.23 & 0.26 & 0.22 & 0.27 & 0.29 & 0.28 & 0.18 & 0.20 & 0.24 & 0.28 & 0.20 & 0.14 \\
\hline COWAT & 0.27 & 0.29 & 0.11 & 0.12 & 0.23 & 0.25 & 0.28 & 0.11 & 0.12 & 0.27 & 0.24 & 0.28 & 0.09 & 0.08 & 0.26 \\
\hline WAIS-RF & 0.24 & 0.29 & 0.23 & 0.24 & 0.26 & 0.26 & 0.25 & 0.27 & -0.25 & 0.14 & 0.29 & -0.21 & 0.25 & -0.17 & 0.20 \\
\hline WAIS-RB & 0.14 & 0.17 & 0.19 & 0.14 & -0.27 & 0.25 & 0.10 & 0.18 & 0.25 & 0.21 & -0.13 & -0.13 & 0.16 & 0.24 & 0.29 \\
\hline CTT1 & 0.29 & 0.23 & 0.16 & 0.22 & 0.26 & 0.18 & 0.13 & 0.11 & 0.28 & -0.24 & 0.22 & 0.25 & 0.23 & 0.19 & 0.25 \\
\hline CTT2 & 0.13 & 0.70 & -0.08 & 0.23 & 0.26 & 0.24 & 0.29 & 0.30 & -0.29 & 0.22 & 0.27 & -0.13 & 0.10 & 0.13 & 0.17 \\
\hline LM 2R & -0.18 & 0.17 & 0.28 & 0.14 & 0.21 & 0.20 & -0.09 & 0.26 & 0.29 & 0.16 & 0.26 & 0.30 & 0.15 & 0.14 & 0.19 \\
\hline CVLT TL & 0.10 & 0.26 & 0.17 & 0.23 & 0.28 & 0.04 & 0.23 & 0.13 & 0.25 & 0.19 & -0.18 & 0.24 & 0.29 & 0.26 & 0.19 \\
\hline \multicolumn{16}{|c|}{ Urodynamic marker } \\
\hline PVR (mL) & $-0.45^{*}$ & $-0.51^{*}$ & -0.29 & $-0.27^{\star}$ & $-0.32^{*}$ & -0.29 & $-0.39^{*}$ & -0.34 & -0.25 & $-0.27^{\star}$ & $-0.28^{\star}$ & -0.13 & -0.19 & 0.03 & -0.15 \\
\hline Qaver (mL/sec) & 0.37 & 0.25 & $0.47^{\star}$ & 0.37 & 0.39 & $0.24^{\star}$ & $-0.56^{*}$ & $-0.51^{*}$ & -0.29 & $-0.52^{\star}$ & -0.46 & -0.33 & -0.38 & $-0.30^{*}$ & -0.27 \\
\hline Urgency & $-0.64^{*}$ & $-0.75^{\star}$ & -0.49 & $-0.41^{\star}$ & $-0.38^{*}$ & -0.33 & $-0.73^{*}$ & $-0.61^{\star}$ & $-0.49^{*}$ & $-0.64^{\star}$ & $-0.55^{\star}$ & -0.48 & $-0.67^{\star}$ & $-0.65^{\star}$ & $-0.55^{\star}$ \\
\hline UUI & $-0.76^{*}$ & $-0.61^{*}$ & $-0.52^{*}$ & $-0.63^{*}$ & $-0.57^{\star}$ & -0.35 & $-0.55^{\star}$ & $-0.56^{*}$ & $-0.38^{\star}$ & $-0.83^{\star}$ & $-0.80^{*}$ & $-0.53^{\star}$ & $-0.73^{\star}$ & $-0.78^{\star}$ & $-0.33^{*}$ \\
\hline ICIQ-SF & $-0.66^{*}$ & -0.52 & $-0.47^{\star}$ & $-0.74^{*}$ & $-0.41^{\star}$ & $-0.45^{\star}$ & $-0.66^{\star}$ & $-0.45^{\star}$ & $-0.39^{*}$ & $-0.75^{\star}$ & $-0.49^{*}$ & $-0.24^{*}$ & $-0.62^{*}$ & $-0.57^{\star}$ & -0.31 \\
\hline
\end{tabular}

Group A, solifenacin $20 \mathrm{mg}$ + trospium $60 \mathrm{mg}$ per day; group B, solifenacin $10 \mathrm{mg}$ + trospium $30 \mathrm{mg}$ per day; group C, control (placebo); HRQoL, health-related quality of life markers; MOS-36, Medical Outcomes Study 36-Item; PF, physical functioning; GHP, general health perceptions; PRF, physical role functioning; ERF, emotional role functioning; SRF, social role functioning; MMSE, Mini-Mental State Examination; COWAT, Controlled Oral Word Association Test; WAIS-R, Wechsler Adult Intelligence Scale-Revised; WAIS-RF, digit span forward; WAIS-RB, digit span backward; CTT1, Color Trails Test 1; CTT2, Color Trails Test 2; LM 2R, logic memory 2 recognition (WMS-III); CVLT TL, California Verbal Learning Test TL; PVR, postvoid residual (urine volume); Qaver, average volumetric rate of urination; UUI, urgency urinary incontinence; ICIQ-SF, International Consultation on Incontinence Questionnaire-Short Form (score point).

Spearmen coefficient $\left({ }^{*} \mathrm{P}<0.05\right)$. 
Table 4. The relationship between assessment of level of cognitive performance and the symptoms of lower urinary tract according Spearman coefficient $(\mathrm{n}=312)$

\begin{tabular}{|c|c|c|c|c|c|c|c|c|c|c|c|c|c|c|c|}
\hline \multirow{4}{*}{ Cognitive marker } & \multicolumn{15}{|c|}{ Urodynamic marker } \\
\hline & \multicolumn{3}{|c|}{ PVR } & \multicolumn{3}{|c|}{ Qaver } & \multicolumn{3}{|c|}{ Urgency } & \multicolumn{3}{|c|}{ UUI } & \multicolumn{3}{|c|}{ ICIQ-SF } \\
\hline & \multicolumn{3}{|c|}{ Group } & \multicolumn{3}{|c|}{ Group } & \multicolumn{3}{|c|}{ Group } & \multicolumn{3}{|c|}{ Group } & \multicolumn{3}{|c|}{ Group } \\
\hline & $\mathrm{A}$ & B & $\mathrm{C}$ & A & B & $\mathrm{C}$ & A & B & $\mathrm{C}$ & A & B & $\mathrm{C}$ & A & B & $\mathrm{C}$ \\
\hline MMSE & 0.13 & -0.10 & -0.09 & 0.09 & 0.15 & -0.21 & $0.41^{\star}$ & -0.44 & -0.12 & $0.48^{*}$ & -0.06 & -0.12 & $-0.36^{\star}$ & -0.28 & 0.14 \\
\hline COWAT & -0.11 & 0.19 & -0.21 & -0.29 & $-0.25^{*}$ & -0.14 & -0.17 & -0.22 & 0.27 & 0.24 & 0.24 & -0.16 & -0.15 & -0.23 & -0.28 \\
\hline WAIS-RF & -0.21 & -0.26 & -0.02 & -0.12 & -0.17 & -0.23 & -0.13 & -0.17 & 0.16 & -0.24 & -0.29 & 0.08 & -0.14 & -0.07 & -0.03 \\
\hline WAIS-RB & -0.15 & -0.27 & -0.24 & -0.16 & -0.23 & -0.11 & -0.26 & -0.14 & 0.17 & 0.15 & -0.18 & -0.04 & -0.16 & 0.17 & 0.12 \\
\hline CTT1 & -0.24 & -0.25 & -0.05 & 0.17 & -0.13 & -0.15 & 0.16 & -0.14 & 0.21 & -0.16 & -0.17 & -0.07 & 0.16 & -0.19 & -0.16 \\
\hline CTT2 & -0.16 & -0.24 & -0.20 & -0.24 & -0.26 & -0.07 & $-0.36^{*}$ & -0.21 & -0.14 & -0.31 & -0.18 & -0.13 & $-0.33^{\star}$ & -0.27 & -0.24 \\
\hline $\mathrm{LM} 2 \mathrm{R}$ & 0.05 & 0.13 & -0.15 & 0.15 & -0.13 & -0.14 & -0.18 & -0.06 & -0.11 & -0.21 & -0.17 & -0.10 & -0.30 & 0.14 & -0.24 \\
\hline CVLT TL & -0.23 & -0.28 & -0.12 & -0.15 & -0.17 & -0.18 & -0.23 & -0.08 & 0.21 & -0.16 & -0.09 & -0.28 & -0.16 & -0.12 & -0.13 \\
\hline
\end{tabular}

Group A, solifenacin $20 \mathrm{mg}$ + trospium $60 \mathrm{mg}$ per day; group B, solifenacin $10 \mathrm{mg}$ + trospium $30 \mathrm{mg}$ per day; group C, control (placebo); PVR, postvoid residual (urine volume); Qaver, average volumetric rate of urination; UUI, urgency urinary incontinence (episodes); ICIQ-SF, International Consultation on Incontinence Questionnaire-Short Form (score point); MMSE, Mini-Mental State Examination; COWAT, Controlled Oral Word Association Test; WAIS-R, Wechsler Adult Intelligence Scale-Revised; WAIS-RF, digit span forward; WAIS-RB, digit span backward; CTT1, Color Trails Test 1; CTT2, Color Trails Test 2; LM 2R, logic memory 2 recognition (WMS-III); CVLT TL, California Verbal Learning Test TL. Spearmen coefficient $\left({ }^{*} \mathrm{P}<0.05\right)$.

rameters and cognitive markers in any of the elderly women who took part in the study (Table 3). However, the values of the urodynamic parameter of urgency in groups A and B had a strong negative correlation with the HRQoL parameters of $\mathrm{PF}$, $\mathrm{PRF}, \mathrm{ERF}$, and SRF, in the range of $\mathrm{r}=-0.61$ to $-0.75(\mathrm{P}<0.05)$. The correlation of UUI with PF, GHP, ERF, and SRF was $r=$ -0.61 to $-0.83(\mathrm{P}<0.05)$ for these groups. In group $\mathrm{A}$, a strong correlation of ICIQ-SF parameters with all parameters of HRQoL ( $r=-0.62$ to $-0.75, \mathrm{P}<0.05$ ) was found.

In most cases, we were only able to establish a weak correlation between the functional indices of LUTS and markers of cognitive status. However, in group A, a moderate correlation was found between the values of MMSE and CTT2 with the values of urgency, UUI, and ICIQ-SF $(r=-0.31,-0.48 ; \mathrm{P}<0.05)$ (Table 4).

The construction of linear regressions (data not shown) confirmed the presence of strong links between most HRQoL parameters and lower urinary tract function. However, we did not find a correlation between cognitive status and HRQoL. Additionally, no significant correlation was found between cognitive status and lower urinary tract function.

\section{DISCUSSION}

The problem of managing the symptoms of urinary incontinence is still relevant. UUI and MUI have a high prevalence in the female population, and are associated with a decline in quality of life and high economic costs $[5,6]$. New AMs are safe and very effective, but do not always lead to the desired results $[28,29]$. A promising way to manage treatment-resistant UUI and MUI is to prescribe a combination of 2 drugs that have a different spectrum of effects on M-cholinergic receptors at the usual dosage or at an increased dosage. The effectiveness of combined therapy on UUI, MUI, and overactive bladder has been shown in many studies $[18,19,30]$. However, the effects of this treatment strategy on cognitive function and HRQoL in patients with urinary incontinence have not been studied.

In this study, we showed that cognitive function did not decrease in older women who took a combination of solifenacin and trospium at standard and doubled doses. In groups $\mathrm{A}$ and $\mathrm{B}$, the perception of information, the processing and analysis of information, the memorisation and storage of information, the exchange of information, and the construction and implementation of a program of actions did not differ significantly from baseline after 2 months of AM administration. In addition, cognitive function in women taking higher doses of AM did 
not differ from cognitive function in the control group. These findings are not consistent with the recent findings of a study [31] that found cognitive decline and decreased semantic memory/language and executive function. However, that study did not analyse the specific effects of individual AMs. The patients who took a combination of AMs in that study were a homogeneous group. However, it is known that solifenacin and trospium hardly penetrate the blood-brain barrier, while oxybutynin molecules easily pass through it. It is possible that the decline in cognitive function in that study occurred precisely in patients taking oxybutynin. Some other authors have pointed out the need for cautious use of AMs in the elderly because of the potential for cognitive impairment [16,17]. Nevertheless, in our opinion, our results convincingly demonstrate the safety of using a combination of solifenacin and trospium in patients resistant to conventional therapies for UUI and MUI.

The values of the basic HRQoL parameters, such as PF, GHP, GRF, and ERF, at the end of the study period were, as expected, significantly higher in patients in groups $\mathrm{A}$ and $\mathrm{B}$ than in the control group $(\mathrm{P}<0.05, \mathrm{P}<0.01)$. The SRF scores in group $\mathrm{A}$ after treatment were higher than in group $\mathrm{B}(\mathrm{P}<0.05)$ or in group $\mathrm{C}(\mathrm{P}<0.01)$. This is in good agreement with the data reported by other investigators on the effects of AM on HRQoL [32,33], but studies of patients taking a combination of solifenacin and trospium have not previously been conducted. The positive effects of AMs on HRQoL are obviously associated with improvements in the functional status of the lower urinary tract.

In the course of this study, we also confirmed previous data on the effectiveness of combining high doses of solifenacin and trospium to correct severe symptoms of UUI and MUI $[18,19]$. The reasons for the lack of a difference in the number of side effects in women taking standard and higher doses of these medications are controversial. We are inclined to explain this phenomenon in light of specific aspects of patients' psychoemotional conditions. By the time the experiment began, all patients had multiple unsuccessful or minimally successful experiences of treatment of UUI and MUI. We know that urinary incontinence extensively restricts social functions, the ability to freely use public transport, and thus has a negative effect on patients' psychoemotional status. It can be assumed that in this context, many patients taking large doses of AMs with high expectations for the success of treatment tend to underestimate the side effects, to tolerate mild complications, and to overlook and even hide them, hoping for a good final result. In the course of the study, a moderate to strong negative correlation was found be- tween the HRQoL scores of patients and the level of disturbances in the functional status of the LUT, which is in good agreement with the data reported by other authors on the relationship between the severity of LUTS and HRQoL [30]. The absence of a significant correlation between urodynamics and HRQoL on the one hand, and the parameters of cognitive function on the other hand, in our opinion, also confirms the safety of administering high doses of solifenacin and trospium to elderly women with treatment-resistant UUI and MUI.

In a previous study, we repeatedly noted a reduction in the postvoid residual volume in patients who took solifenacin and trospium. This unusual effect might be explained by the indirect effect of these drugs on the entire system of autonomic regulation of the lower urinary tract. Several researchers in recent years have discussed the theory of the development of "afferent noise" in a local area of the autonomic nervous system that innervates the detrusor in elderly patients [34,35]. It is possible that when suppressing excess afferent impulses with AM drugs, the regulatory function of the intramural ganglia is restored, which leads to a certain decrease in the residual urine volume in patients. However, we do not consider this explanation to be conclusive and further research is needed.

We are, of course, aware that the therapeutic regimen described herein has certain limitations. Further study is needed to investigate the effects of increased doses of AM drugs on the cognitive function of persons with already existing cognitive impairments. We also did not investigate the possibility of gradually reducing the AM dose in patients who experienced a good therapeutic effect after 2 months of treatment. This study aimed to study the safety of high doses of AM in terms of cognitive function in the short term. However, reducing the 'drug load' on elderly patients while maintaining the therapeutic effect is an important problem in clinical practice. Therefore, we believe that further research with a different study design is required to investigate these issues.

The study has some other limitations. The postvoid residual volume in 27 women (8.6\%) (13 in group A, 6 in group B, and 8 in group C) was $>50 \mathrm{~mL}$. In our study, none of these women had any complications when taking elevated doses of AM. However, we consider it necessary to further study the safety of taking high doses of solifenacin and trospium in these patients. In addition, we did not employ a temporary or constant dose reduction in patients with side effects, which is an issue that requires further study.

In conclusion, the simultaneous administration of higher 
doses of solifenacin and trospium did not affect the cognitive ability of women with incontinence resistant to standard therapy. The health-associated quality of life in these women significantly increased. An inverse correlation was found between HRQoL and symptoms of urinary incontinence, but no correlation was found between cognitive function and lower urinary tract function.

Thus, the simultaneous administration of higher doses of solifenacin and trospium is an effective and safe method for correcting incontinence in elderly women and can be recommended for elderly patients who are resistant to conventional therapies. However, the safety of combining AM drugs in women with increased residual urine volume requires further study.

\section{AUTHOR CONTRIBUTION STATEMENT}

- Full access to all the data in the study and takes responsibility for the integrity of the data and the accuracy of the data analysis: K. Kosilov

-Study concept and design: K. Kosilov

- Acquisition of data: S. Loparev A. Prokofyeva

- Analysis and interpretation of data: K. Kosilov, Y. Gainullina

- Drafting of the manuscript: Kosilov $K$

-Critical revision of the manuscript for important intellectual content: I. Kuzina, L. Kosilova

- Statistical analysis: K. Kosilov, Y. Gainullina

- Obtained funding: Kuzina I

- Administrative, technical, or material support: Y. Gainullina, A. Prokofyeva

-Study supervision: K. Kosilova

\section{REFERENCES}

1. Abrams P, Andersson KE, Birder L, Brubaker L, Cardozo L, Chapple $C$, et al. Fourth International Consultation on Incontinence Recommendations of the International Scientific Committee: Evaluation and treatment of urinary incontinence, pelvic organ prolapse, and fecal incontinence. Neurourol Urodyn 2010;29:213-40.

2. Pfisterer MH, Griffiths DJ, Schaefer W, Resnick NM. The effect of age on lower urinary tract function: a study in women. J Am Geriatr Soc 2006;54:405-12.

3. Coyne KS, Sexton CC, Bell JA, Thompson CL, Dmochowski R, Bavendam $\mathrm{T}$, et al. The prevalence of lower urinary tract symptoms (LUTS) and overactive bladder (OAB) by racial/ethnic group and age: results from OAB-POLL. Neurourol Urodyn 2013;32:230-7.

4. Sensoy N, Dogan N, Ozek B, Karaaslan L. Urinary incontinence in women: prevalence rates, risk factors and impact on quality of life. Pak J Med Sci 2013;29:818-22.

5. Coyne KS, Payne C, Bhattacharyya SK, Revicki DA, Thompson C, Corey R, et al. The impact of urinary urgency and frequency on health-related quality of life in overactive bladder: results from a national community survey. Value Health 2004;7:455-63.

6. Kogan MI, Zachoval R, Ozyurt C, Schäfer T, Christensen N. Epidemiology and impact of urinary incontinence, overactive bladder, and other lower urinary tract symptoms: results of the EPIC survey in Russia, Czech Republic, and Turkey. Curr Med Res Opin 2014;30:2119-30.

7. Shamliyan T, Wyman JF, Ramakrishnan R, Sainfort F, Kane RL. Benefits and harms of pharmacologic treatment for urinary incontinence in women: a systematic review. Ann Intern Med 2012;156: 861-74, W301-10.

8. Kosilov KV, Loparev SA, Ivanovskaya MA, Kosilova LV. Comparative effectiveness of combined low- and standard-dose trospium and solifenacin for moderate overactive bladder symptoms in elderly men and women. Urol Int 2014;93:470-3.

9. Kosilov K, Loparev S, Ivanovskaya M, Kosilova L. A randomized, controlled trial of effectiveness and safety of management of $\mathrm{OAB}$ symptoms in elderly men and women with standard-dosed combination of solifenacin and mirabegron. Arch Gerontol Geriatr 2015;61:212-6.

10. Erdem N, Chu FM. Management of overactive bladder and urge urinary incontinence in the elderly patient. Am J Med 2006;119(3 Suppl 1):29-36.

11. Gibson W, Wagg A, Hunter KF. Urinary incontinence in older people. Br J Hosp Med (Lond) 2016;77:C27-32.

12. Cipullo LM, Cosimato C, Filippelli A, Conti V, Izzo V, Zullo F, et al. Pharmacological approach to overactive bladder and urge urinary incontinence in women: an overview. Eur J Obstet Gynecol Reprod Biol 2014;174:27-34.

13. Cardozo L, Amarenco G, Pushkar D, Mikulas J, Drogendijk T, Wright $\mathrm{M}$, et al. Severity of overactive bladder symptoms and response to dose escalation in a randomized, double-blind trial of solifenacin (SUNRISE). BJU Int 2013;111:804-10.

14. Salvatore S, Serati M, Cardozo L, Uccella S, Bolis P. Cognitive dysfunction with tolterodine use. Am J Obstet Gynecol 2007;197:e8.

15. Pagoria D, O'Connor RC, Guralnick ML. Antimuscarinic drugs: review of the cognitive impact when used to treat overactive bladder in elderly patients. Curr Urol Rep 2011;12:351-7.

16. Wagg A, Dale M, Tretter R, Stow B, Compion G. Randomised, 
multicentre, placebo-controlled, double-blind crossover study investigating the effect of solifenacin and oxybutynin in elderly people with mild cognitive impairment: the SENIOR study. Eur Urol 2013;64:74-81.

17. Geller EJ, Dumond JB, Bowling JM, Khandelwal CM, Wu JM, Busby-Whitehead J, et al. Effect of trospium chloride on cognitive function in women aged 50 and older: a randomized trial. Female Pelvic Med Reconstr Surg 2017;23:118-23.

18. Kosilov K, Loparev S, Ivanovskaya M, Kosilova L. Maintenance of the therapeutic effect of two high-dosage antimuscarinics in the management of overactive bladder in elderly women. Int Neurourol J 2013;17:191-6.

19. Kosilov K, Loparev S, Kosilova L, Ivanovskaya M. Comparative effectiveness of combined high-dosed Trospium and Solifenacin for severe OAB symptoms in age-related aspect. Int J Urol Nurs 2015; 9:108-13.

20. Chancellor M, Boone T. Anticholinergics for overactive bladder therapy: central nervous system effects. CNS Neurosci Ther 2012;18:167-74.

21. Wagg A, Verdejo C, Molander U. Review of cognitive impairment with antimuscarinic agents in elderly patients with overactive bladder. Int J Clin Pract 2010;64:1279-86.

22. Kim A, Lee KS, Jung R, Na S, Kim JC, Kim HG, et al. Health related quality of life in patients with side-effects after antimuscarinic treatment for overactive bladder. Low Urin Tract Symptoms 2017; 9:171-5.

23. Howland M, Tatsuoka C, Smyth KA, Sajatovic M. Detecting change over time: a comparison of the SLUMS examination and the MMSE in older adults at risk for cognitive decline. CNS Neurosci Ther 2016;22:413-9.

24. Demir O, Sen V, Irer B, Bozkurt O, Esen A. Prevalence and possible risk factors for urinary incontinence: a cohort study in the city of Izmir. Urol Int 2017;99:84-90.

25. Kim SH, Oh SA, Oh SJ. Voiding diary might serve as a useful tool to understand differences between bladder pain syndrome/interstitial cystitis and overactive bladder. Int J Urol 2014;21:179-83.
26. Okada T, Kono Y, Matsumoto K, Sumiyoshi T, Masuda N, Shiraishi $\mathrm{Y}$, et al. The impact of lower urinary tract symptoms on generic health-related quality of life in male patients without co-morbidity. Nihon Hinyokika Gakkai Zasshi 2015;106:172-7.

27. Kosilov KV, Alexandrovich LS, Gennadyevna KI, Viktorovna SO, Sergeevna ZN, Ivanovich AI. Social, economic, and medical factors associated with solifenacin therapy compliance among workers who suffer from lower urinary tract symptoms. Int Neurourol J 2016;20:240-9.

28. Tugtepe H, Thomas DT, Ergun R, Kalyoncu A, Kaynak A, Kastarli $\mathrm{C}$, et al. The effectiveness of transcutaneous electrical neural stimulation therapy in patients with urinary incontinence resistant to initial medical treatment or biofeedback. J Pediatr Urol 2015; 11:137.el-5.

29. Gomelsky A, Dmochowski RR. Treatment of mixed urinary incontinence. Cent European J Urol 2011;64:120-6.

30. Cardozo L, Hall T, Ryan J, Ebel Bitoun C, Kausar I, Darekar A, et al. Safety and efficacy of flexible-dose fesoterodine in British subjects with overactive bladder: insights into factors associated with dose escalation. Int Urogynecol J 2012;23:1581-90.

31. Moga DC, Abner EL, Wu Q, Jicha GA. Bladder antimuscarinics and cognitive decline in elderly patients. Alzheimers Dement (N Y) 2017;3:139-48.

32. Abrams P, Kelleher C, Huels J, Quebe-Fehling E, Omar MA, Steel M. Clinical relevance of health-related quality of life outcomes with darifenacin. BJU Int 2008;102:208-13.

33. Tang DH, Colayco DC, Khalaf KM, Piercy J, Patel V, Globe D, et al. Impact of urinary incontinence on healthcare resource utilization, health-related quality of life and productivity in patients with overactive bladder. BJU Int 2014;113:484-91.

34. Andersson KE. The use of pharmacotherapy for male patients with urgency and stress incontinence. Curr Opin Urol 2014;24:571-7.

35. Andersson KE, Boedtkjer DB, Forman A. The link between vascular dysfunction, bladder ischemia, and aging bladder dysfunction. Ther Adv Urol 2017;9:11-27. 